\title{
Method validation for the simultaneous estimation of three-bioactive components in combined extracts of three hepatoprotective plants using RP-HPLC method
}

\author{
Sharuti Mehta ${ }^{1,4}$ (D), Anil Kumar Sharma ${ }^{2}$ (D), Rajesh Kumar Singh ${ }^{3 *}$ \\ ${ }^{1} \mathrm{CT}$ Institute of Pharmaceutical Sciences, Jalandhar, India. \\ ${ }^{2}$ AIMIL Pharmaceuticals India Limited, Delhi, India. \\ ${ }^{3}$ Department of Pharmaceutical Chemistry, Shivalik College of Pharmacy, Nangal, India. \\ ${ }^{4}$ Research Scholar at IKG Punjab Technical University, Kapurthala, 144601, India.
}

\section{ARTICLE INFO \\ Received on: 05/02/2021 \\ Accepted on: 29/04/2021 \\ Available online: 05/07/2021}

\section{Key words:}

Diterpeniod lactone,

flavanolignan, high

performance liquid

chromatography, kalmegh,

kutki, milk thistle.

\begin{abstract}
Picrorhiza kurroa Royle ex Benth. (Scrophulariaceae), Andrographis paniculata (Burm.f.) Nees (Acanthaceae), Silybum marianum (L.) Gaernt (Sm). (Asteraceae) are well-known plants to treat various ailments. Simultaneous quantification and determination of picroside-I, andrographolide, and silybin were conducted in the combined extract of their respective plants, by reverse-phase high performance liquid chromatography (RP-HPLC). Analytical determination of the proposed HPLC method was validated as per referenced protocol. Determination and method validation was carried on RP-HPLC column. Picroside-I, andrographolide, and silybin were quantified as 1.232 $\pm 0.0102,0.572 \pm 0.0734,2.037 \pm 0.0635 \mu \mathrm{g} / \mathrm{mg}$, respectively. Validated method for simultaneous estimation of analytes was investigated to be linear, specific, reproducible, and accurate. Recovery of identified analytes was within the specified limit of $99.65 \%-102.59 \%$. The study reveals that the developed HPLC method exhibits potential for determination and quantification of picroside-I, andrographolide, and silybin in in combined extract of P. kurroa, A. paniculata, and S. marianum.
\end{abstract}

\section{INTRODUCTION}

Natural products specifically plants are leading source of biologically active compounds, which are used to treat various human and animal ailments. It is estimated that worldwide, $80 \%$ of the people in developing countries are dependent on traditional medicines and medicinal plants for their basic healthcare requirements (Mahady, 2001). Plant-based medicines consist of a single herb or are combination of many herbs containing multiple chemical components. Thus, quality control of such combinations sets a great challenge. Fingerprinting investigation has emerged as an important analytical method for quality control of synthetic as well as herbal drugs. It offers essential characterization of a complex mixture with a quantitative extent of reliability and aims on

\section{${ }^{*}$ Corresponding Author}

Rajesh Kumar Singh, Department of Pharmaceutical Chemistry, Shivalik College of Pharmacy, Nangal, India.E-mail:rksingh244@gmail.com the detection and stability evaluation of the components (Alamgir, 2017; Xie et al., 2007). Modern analytical methods viz. High performance liquid chromatography (HPLC), high performance thin layer chromatography, and gas chromatography are exercised worldwide to obtain the fingerprint analysis of single as well as complex herbal drugs (Martin and Guiochon, 2005). HPLC is a widely accepted and robust method to isolate and separate mixture of components of natural products. Additionally, it permits the identification, quantification, and purification of components in a mixture (Fan et al., 2006; Govindarajan et al., 2019). This approach is currently being recognized among numerous analytical methods as the primary choice for fingerprinting investigation to validate the quality control of herbal drugs (Gamal et al., 2019; Li et al., 2008; Liang et al., 2020; Srivastava et al., 2015; Wang et al., 2019). Silybum marianum (L.) Gaernt (Sm). (Asteraceae), Andrographis paniculata (Burm.f.) Nees (Acanthaceae), Picrorhiza kurroa Royle ex Benth. (Scrophulariaceae) are the recognized hepatoprotective plants. 
Picrorhiza kurroa contains iridoid glycosides, cucurbitacin glycosides, apocynin, kutkin, and picrosides as its bioactive constituents. Picroliv or Kutkin is the most important iridoid glycoside of the plant, accountable for the hepatoprotective activity and is a combination of kutkoside and picroside-I (Khare, 2007; Mehta et al., 2021a). Numerous research works have highlighted the hepatoprotective potential of P. kurroa in different animal models (Shetty et al., 2010; Sinha et al., 2011; Talmale et al., 2010). Picroside-I has been reported as a bioactive component, which is responsible for the hepatoprotective activity of P. kurroa (Dwivedi et al., 1992). The compound has shown its hepatoprotective potential in hepatic fibrosis by regulating the sphingolipid signaling pathway, biosynthesis of primary bile acid, and peroxisome proliferator-triggered receptor signaling pathway (Xiong et al., 2020). Picrorhiza kurroa has also exhibited hepatoprotective activity against $\mathrm{CCl}_{4}$ induced hepatotoxicity and acetaminophen-induced hepatic injury (Gupta et al., 2016; Kaur et al., 2012).

Andrographis paniculata, commonly known as King of Bitters or kalmegh, has scientifically explored for various biological activities including hepatoprotective, anticancer, antioxidant, antibacterial, neuroprotective, immunomodulatory, anti-diabetic, and anti-inflammatory (Mehta et al; 2021b, 2021c; Parveen et al., 2019). Diterpene lactones are responsible for the multiple biological applications of $A$. paniculata. Among various diterpene lactones, andrographolide has been widely investigated. It has ameliorated the liver injury by decreasing the oxidative stress and inflammatory responses (Chen et al., 2014; Ye et al., 2011) and showed a protective effect for acute intrahepatic cholestasis by suppressing $\mathrm{NF} \kappa \mathrm{B}$ expression and suppression of hepatic stellate cell activation (Khamphaya et al., 2016).

Silymarin is the standardized extract of $S$. marianum (Milk Thistle) seeds, consisting of various flavonolignans (about $70 \%-80 \% w / w)$ and oxidized and polymeric polyphenolic components including the combination of flavonoids. The key components of silymarin are silybin, isosilybin, silychristin, isosilychristin, silydianin, and silimonin (Poppe and Petersen, 2016). Silybin is the active compound of the extract, which have been validated by different scientific reports and present in a range of $20 \%-40 \%$ in various pharmaceutical products containing silymarin (Bijak, 2017; Bijak et al., 2014). Silymarin and silybin have shown significant hepatoprotective, antioxidant, chemopreventing, and anti-inflammatory activities (Abenavoli et al., 2016; Mastron et al., 2015; Serviddio et al., 2014; Zhu et al., 2016).

Several methods are available to estimate bioactive constituents individually and/or in combination with other components in their respective plants (Korany et al., 2017; Patel et al., 2008; Singh et al., 2005). As per the literature survey, although these three plants are explored individually and in combination with other drugs to treat various hepatic diseases, but to the best of authors' knowledge, there is no report of any analytical study published for these three plants. Therefore, we selected these plants and developed the HPLC method for the simultaneous determination of the three bioactive components of these hepatoprotective plants viz. andrographolide (for $A$. paniculata), picroside-I (for P. kurroa), silybin (for S. marianum), when they are used in a mixture. Our aim is to establish and validate HPLC approach for simultaneous determination of the three bioactive markers, in the combined extract attained by mixing kalmegh, kutki, and milk thistle. The developed method was validated as per the referenced protocol.

\section{Experimental}

\section{Plant material and authentication}

Andrographis paniculata (aerial parts), P. kurroa (roots), and $S$. marianum (seeds) were provided as gift samples by AIMIL Pharmaceuticals India Limited, Ranjeet Nagar, New Delhi and authenticated by Dr. H.B. Singh-Chief Scientist and Head, Raw Materials Herbarium and Museum, National Institute of Science Communication and Information Resources, New Delhi vide certificate no. A/RM/2017/1352 (A. paniculata), A/RM/2017/1311 (P. kurroa), A/RM/2017/1383 (S. marianum).

\section{Material and Methods}

HPLC system (LC-2010 CHT series chromatographic system, Shimadzu, Japan), equipped with SPD-10 AVP UVVisible spectrophotometric detector was used for the present study. All the chemicals and solvents used for present study were of analytical grade (AR) and are procured from the Merck (Mumbai, India) and SD Fine Chemicals (New Delhi, India). Water was obtained in the laboratory using (PURELAB Flex 2, ELGA) water purification system.

\section{Physicochemical evaluation}

The physicochemical parameters like ash values, extractive values, loss on drying (LOD) A. paniculata, P. kurroa, and $S$. marianum were determined as per the standard protocol of The Ayurvedic Pharmacopoeia of India (Anonymous, 2007).

\section{Preparation of extracts}

Each powdered $(100 \mathrm{~g})$ drug (P. kurroa, A. paniculata and $S$. marianum) was weighed using an analytical balance. The crude material of each drug was soaked in $700 \mathrm{ml}$ of hydroalcoholic solvent $(7: 3, v / v)$ for overnight at room temperature followed by extraction using the reflux method for 8 hours at $60^{\circ} \mathrm{C}$. The extracts were then filtered. The filtrates were evaporated on a water bath $\left(60^{\circ} \mathrm{C}\right)$ to get dried residues which were kept in airtight containers for further study (Farahmandfar et al., 2019; Mukherjee et al., 2008).

\section{Sample and stock solutions preparation}

The stock solutions of all samples were prepared along with reference marker compounds, picroside-I, andrographolide, and silybin. In brief, $1 \mathrm{mg}$ of each sample and marker compound were dissolved in methanol and filtered through $0.22 \mu$ PEP filter before analysis. Furthermore, all the drug samples were mixed in $1: 1: 1 v / v / v$ ratio to obtained mix sample.

\section{Qualitative and quantitative analysis using HPLC method}

Qualitative and quantitative analysis were performed for estimation of picroside-I, andrographolide, and silybin in $P$. kurroa, A. paniculate, and $S$. marianum, respectively, using HPLC system (LC-2010 CHT series chromatographic system, Shimadzu, Japan) which consisted of a Model LC-10 ATVP binary pump 
Table 1. Physicochemical parameters of the A. paniculata, P. kurroa and S. marianum.

\begin{tabular}{|c|c|c|c|c|c|c|}
\hline Plant name & $\begin{array}{l}\text { Foreign matter } \\
\quad(\% w / w)\end{array}$ & $\begin{array}{l}\text { LOD }(\% \\
w / w)\end{array}$ & $\begin{array}{c}\text { Total ash }(\% \\
w / w)\end{array}$ & $\begin{array}{l}\text { Acid insoluble ash } \\
\qquad(\% w / w)\end{array}$ & $\begin{array}{l}\text { Alcohol soluble extractive } \\
\qquad(\% w / w)\end{array}$ & $\begin{array}{c}\text { Water soluble extractive } \\
(\% w / w)\end{array}$ \\
\hline A. paniculata & 0.02 & 6.99 & 7.88 & 2.13 & 12.3 & 25.56 \\
\hline P. kurroa & 0.12 & 10.79 & 5.66 & 0.95 & 15.4 & 32.4 \\
\hline S. marianum & 0.12 & 7.2 & 6.42 & 0.65 & 10.4 & 16.8 \\
\hline
\end{tabular}

and equipped with SPD-10 AVP UV-Visible spectrophotometric detector. Class-VP 5.032 software was stated for routine drug analysis. The separation of compounds was conducted using $\mathrm{C}_{18}$ column $(25 \times 4.6 \mathrm{~mm}, 5 \mu)$ at ambient temperature $\left(30^{\circ} \mathrm{C}\right)$ by injection of $10 \mu$ volume of respective solutions. Methanol and water in ratio of 50:50 v/v with $0.1 \%$ of formic acid in isocratic elution mode was used for conducting the analysis, and it was delivered at a flow rate of $0.7 \mathrm{ml}$ minute ${ }^{-1}$. The chromatographic separation time for the system was set up to 30 minutes. All the measurements were taken in triplicate to detect the accuracy of the detector response at every concentration level. Detection was carried out at $270 \mathrm{~nm}$. Moreover, the calibration curve was plotted between obtained area and respective concentration (20-1,250 ng/ inj) of each reference compounds. The validation parameters such as sensitivity, linearity, LOD, and limit of quantification (LOQ), precision, accuracy, and recovery of analytes were determined to validate the developed method as per referenced protocol (Dar et al., 2019; Zahiruddin et al., 2016).

\section{RESULTS}

\section{Physicochemical evaluation}

The results of the physicochemical parameters have shown in the Table 1.

\section{Qualitative and quantitative analysis using HPLC method}

Qualitative and quantitative validation of picroside-I, andrographolide, and silybin in P. kurroa, A. paniculate, and $S$. marianum, respectively, was performed successively using methanol and water $(50: 50 \mathrm{v} / \mathrm{v})$ with $0.1 \%$ of formic acid at isocratic mode showed good separation and resolution. Any further changes in the ratio of methanol: water revealed either poor resolution or tailing. Besides that, for the combined extracts of all the drugs, the same established HPLC method was used. The experimental outcomes reveals that picroside-I, andrographolide and silybin were found to be $1.232 \pm 0.0102,0.572 \pm 0.0734$, and $2.037 \pm 0.0635 \mu \mathrm{g} / \mathrm{mg}$ (Table 2) at the retention time 11.496, 19.452, and 27.027 minutes, respectively. The validation analysis of developed method revealed good linearity at the range 20$1,250 \mathrm{ng} /$ inj with regression equation $757.91 x+11,153,570.57 x$ $+14,903,871.18 x+23,419$, regression coefficient $0.9966 \pm$ $0.0005,0.9983 \pm 0.0007,0.9984 \pm 0.0003$, respectively. The LOD and LOQ for the developed method for estimation of picroside-I, andrographolide, and silybin were found to be 3.639, 4.225, $3.895 \mathrm{ng} / \mathrm{inj}$ and 11.029, 15.329, $14.137 \mathrm{ng} / \mathrm{inj}$, respectively. The LOD and LOQ observation reveals excellent sensitivity of the system with respect to the analytes. The interday and intra-day precision were determine with respect to percentage relative standard deviation (\%RSD) and the results were expressed in the range which was found to be $0.860-1.268$,
Table 2. Reverse-phase high performance liquid chromatography quantification of picroside-I, andrographolide, silybin in the combined extract of all the plants.

\begin{tabular}{ccc}
\hline Standard & Retention time (minute) & Concentration $(\boldsymbol{\mu g} / \mathbf{m g})$ \\
\hline Picroside-I & 11.496 & $1.232 \pm 0.0102$ \\
Andrographolide & 19.452 & $0.572 \pm 0.0734$ \\
Silybin & 27.027 & $2.037 \pm 0.0635$ \\
\hline
\end{tabular}

Table 3. Method validation parameters for the quantification of picroside-I, andrographolide, and silybin by proposed HPLC method.

\begin{tabular}{|c|c|c|c|}
\hline Parameters & Picroside-I & Andrographolide & Silybin \\
\hline $\begin{array}{l}\text { Scanning } \\
\text { wavelength }\end{array}$ & $270 \mathrm{~nm}$ & $270 \mathrm{~nm}$ & $270 \mathrm{~nm}$ \\
\hline $\begin{array}{l}\text { Linearity range } \\
\text { (ng/inj) }\end{array}$ & $20-1,250 \mathrm{ng} / \mathrm{inj}$ & $20-1,250 \mathrm{ng} / \mathrm{inj}$ & $20-1,250 \mathrm{ng} / \mathrm{inj}$ \\
\hline $\begin{array}{l}\text { Regression } \\
\text { equation }\end{array}$ & $757.91 x+11,153$ & $570.57 x+14,903$ & $871.18 x+23,419$ \\
\hline $\begin{array}{l}\text { Regression } \\
\text { coefficient } \pm \mathrm{SD}\end{array}$ & $0.9966 \pm 0.0005$ & $0.9983 \pm 0.0007$ & $0.9984 \pm 0.0003$ \\
\hline Slope \pm SD & $757.91 x \pm 2.845$ & $570.57 x \pm 4.0183$ & $871.18 x \pm 1.9175$ \\
\hline LOD (ng/inj) & 3.639 & 4.225 & 3.895 \\
\hline LOQ (ng/inj) & 11.029 & 15.329 & 14.137 \\
\hline $\begin{array}{l}\text { Interday Precision } \\
(\% \mathrm{RSD} \text { range })\end{array}$ & $0.860-1.268$ & $1.232-1.653$ & $0.779-2.086$ \\
\hline $\begin{array}{l}\text { Intraday Precision } \\
(\% \mathrm{RSD} \text { range })\end{array}$ & $0.753-1.975$ & $0.952-1.667$ & $0.753-1.975$ \\
\hline $\begin{array}{l}\text { Accuracy ( } \% \text { data } \\
\text { recovered) }\end{array}$ & $99.65 \%-101.43 \%$ & $98.75 \%-101.12 \%$ & $99.79 \%-102.59 \%$ \\
\hline
\end{tabular}

1.232-1.653, and 0.779-2.086 for inter-day precision and $0.753-$ $1.975,0.952-1.667$, and $0.753-1.975$ for intra-day precision. The results of inter and intra-day analysis demonstrated that the assessments was within the limit which represents good precision of developed method. Furthermore, the resulted outcomes form accuracy data suggest accurate and robust validation analysis which was confirmed based on percentage drug recovery found as $99.65 \%-101.43 \%, 98.75 \%-101.12 \%$, and $99.79 \%-102.59 \%$, respectively. The simultaneous estimation and determination of picroside-I, andrographolide, and silybin by HPLC method was validated, and found with all the specified parameters within the range. The validated method revealed the adequate separation of analytes in reference mixture with no merging of unknown peaks. It indicated the peak purity was good and thus verifies the method selectivity. Thus, the validation results revealed that the method developed is reproducible with adequate selectivity, sensitivity, and accuracy and precision. The experimental outcomes of validation method have been summarized in Tables 2 and 3 and the chromatograms are displayed in Figures 1 and 2. 


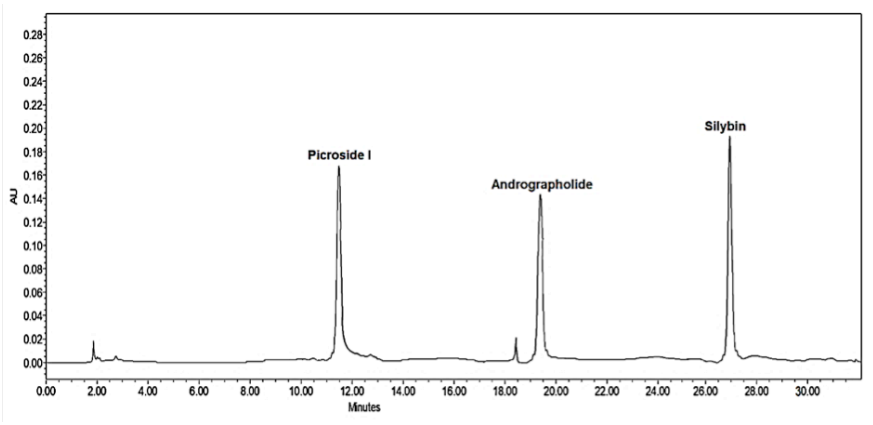

Figure 1. Simultaneous separation of picroside-I, andrographolide, and silybin through HPLC.
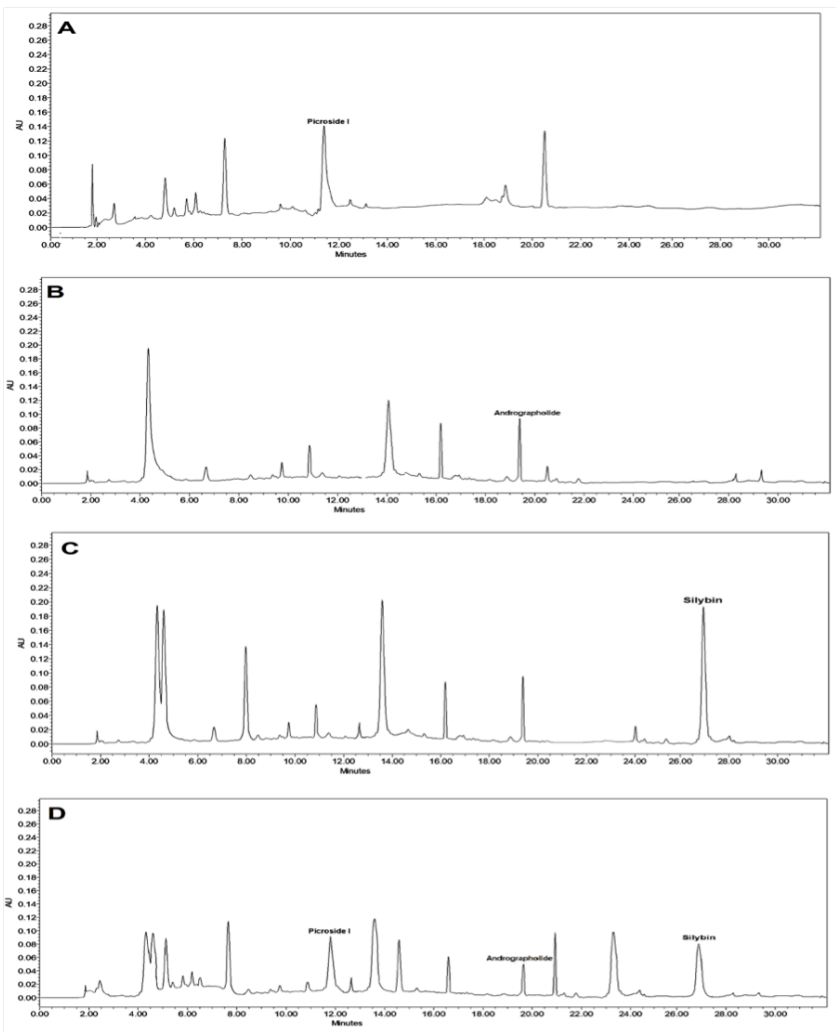

Figure 2. Represents HPLC chromatograms of various plant extracts, where (A) represents the chromatogram of $P$. kurroa, (B) represents the chromatogram of Andrographis paniculata, (C) represents the chromatogram of S. marianum and (D) represents the chromatogram of combined sample of all the drugs in 1:1:1 $v / v / v$ ratio.

\section{CONCLUSION}

In the present work, a validated HPLC method has been developed and validated for simultaneous estimation and quantification of three components viz. picroside-I, andrographolide, and silybin from the combined extract, comprised kutki, kalmegh, and milk thistle extracts. The proposed method was revealed to be precise, accurate, simple, and robust although the time taken for silybin to completely elute out was long. The optimum value of HPLC system for chromatographic separation of silybin was set for 30 minutes, so that elution can be read. However, new method can be developed in future in reducing the elution time of silybin. This method can be used for the quantification and quality control of polyherbal formulations those contain P. kurroa, A. paniculata, and S. marianum as their ingredients. Furthermore, in future, synergistic studies on these three hepatoprotective plants can be taken into consideration for developing novel antihepatic formulations.

\section{ACKNOWLEDGMENTS}

The Authors are thankful to Dr Sayeed Ahmad, Associate Professor of Bioactive Natural Product Laboratory, School of Pharmaceutical Education and Research, Jamia Hamdard, New Delhi for his precious and continuous guidance related to this study. Furthermore, the authors acknowledge the management of CT institute of Pharmaceutical Sciences, Jalandhar Punjab and Management of Shivalik college of Pharmacy, Nangal, Rupnagar, Punjab, and IKG Punjab Technical University, Jalandhar, Punjab for the constant encouragement and support.

\section{FUNDING}

The research is not funded by any agency.

\section{CONFLICT OF INTEREST}

The authors declare that they have no known competing conflict, financial interests or personal relationships that could have appeared to influence the work reported in this paper.

\section{ETHICAL APPROVALS}

This study does not involve experiments on animals or human subjects.

\section{PUBLISHER'S NOTE}

This journal remains neutral with regard to jurisdictional claims in published institutional affiliation.

\section{REFERENCES}

Abenavoli L, Masarone M, Federico A, Rosato V, Dallio M, Loguercio, C, Persico M. Alcoholic hepatitis: pathogenesis, diagnosis and treatment. Rev Recent Clin Trials, 2016; 11:159-66.

Alamgir ANM (2017) Herbal drugs: their collection, preservation, and preparation; evaluation, quality control, and standardization of herbal drugs. In: Alamgir ANM (ed) Therapeutic use of medicinal plants and their extracts: Pharmacognosy, Springer International Publishing, Cham, 2017; 1:453-495.

Anonymous. The ayurvedic pharmacopoeia of India. 1st edition, Government of India Ministry of Health and Family Welfare, Department of Ayrveda, Yoga \& Naturopathy, Unani, Siddha and Homeopathy (Ayush), Delhi, India, Part-II, vol I, 2007.

Bijak M. Flavonolignans-compounds not only for liver treatment. Pol Merkur Lekarski, 2017; 42(247):34-7.

Bijak M, Ponczek MB, Nowak, P. Polyphenol compounds belonging to flavonoids inhibit activity of coagulation factor X. Int J Biol Macromol, 2014; 65:129-35.

Chen HW, Huang CS, Li CC, Lin AH, Huang YJ, Wang TS, Yao HT, Lii CK. Bioavailability of andrographolide and protection against carbon tetrachloride-induced oxidative damage in rats. Toxicol Appl Pharmacol, 2014; 280:1-9.

Dar AA, Sangwan PL, Kumar A. Method validation and simultaneous quantification of five triterpenoids from Codonopsis ovate by high-performance thin-layed chromatography. J Planar Chromatogr Mod TLC, 2019; 32:251-6.

Dwivedi Y, Rastogi R, Garg NK, Dhawan BN. Picroliv and its components kutkoside and picroside I protect liver against galactosamineinduced damage in rats. Pharmacol Toxicol, 1992; 71:383-7. 
Fan XH, Cheng YY, Ye ZL, Lin RC, Qian ZZ. Multiple chromatographic fingerprinting and its application to the quality control of herbal medicines. Anal Chim Acta, 2006; 555:217-24.

Farahmandfar R, Kenari ES, Asnaashari M, Shahrampour D, Bakhshandeh T. Bioactive compounds, antioxidant and antimicrobial activities of Arum maculatum leaves extracts as affected by various solvents and extraction methods. Food Sci Nutr, 2019; 7(2):465-75.

Gamal M, Ali HM, Abdelfatah RM, Magdy MA. A green approach for simultaneous analysis of two natural hepatoprotective drugs in pure forms, capsules and human plasma using HPLC-UV method. Microchem J, 2019; 151:104258.

Govindarajan R, Tejas V, Pushpangadan, P. High-performance liquid chromatography (HPLC) as a tool for standardization of complex herbal drugs. J AOAC Int, 2019; 102(4):986-92.

Gupta P, Tripathi A, Agarwal T, Narayan C, Singh BM, Kumar M, Kumar A. Synergistic protective effect of Picrorhiza along with honey in acetaminophen induced hepatic injury. Indian J Exp Biol, 2016; 54:530-6.

Kaur S, Vetriselvan S, Hemah, C, Gayathiri S, Yaashini A, Singh I, Shankar J. Hepatoprotective activity of aqueous extract of Picrorhiza kurroa in carbon tetra chloride $\left(\mathrm{CCL}_{4}\right)$ induced hepatotoxicity in albino Wistar rats. Int J Pharm Ther, 2012; 3(2):207-14.

Khamphaya T, Chansela P, Piyachaturawat P, Suksamrarn A, Nathanson MH, Weerachayaphorn J. Effects of andrographolide on intrahepatic cholestasis induced by alpha-naphthylisothiocyanate in rats. Eur J Pharmacol, 2016; 789:254-64.

Khare CP. Indian medicinal plants- An illustrated dictionary. Springer-Verlag, Berlin, Germany, pp 485-6, 2007.

Korany MA, Haggag RS, Ragab MAA, Elmallah, OA. A validated stability-indicating HPLC method for simultaneous determination of silymarin and curcumin in various dosage forms. Arab J Chem, 2017; 10:711-25.

Li P, Qi LW, Liu EH, Zhou, JL, Wen, XD. Analysis of Chinese herbal medicines with holistic approaches and integrated evaluation models. Trends Anal Chem, 2008; 27:66-77.

Liang SY, Zeng YC, Jiang QQ, Wua JH, Wu ZZ. Pharmacokinetic studies of multi-bioactive components in rat plasma after oral administration of Xintiantai I extract and effects of guide drug borneol on pharmacokinetics. Chin Herb Med, 2020; 12:79-87.

Mahady GB. Global harmonization of herbal health claims. J Nutr, 2001; 131:1120S-3S.

Martin M, Guiochon G. Effects of high pressure in liquid chromatography. J Chromatogr A, 2005; 1090:16-38.

Mastron, JK, Siveen KS, Sethi G, Bishayee, A. Silymarin and hepatocellular carcinoma: a systematic, comprehensive, and critical review. Anticancer Drugs, 2015; 26:475-86.

Mehta S, Sharma AK, Singh RK. Advances in ethnobotany, synthetic phytochemistry and pharmacology of endangered herb Picrorhiza kurroa (Kutki): A comprehensive review (2010-2020). Mini Rev Med Chem, 2021a. DOI: 10.2174/1389557521666210401090028

Mehta S, Sharma AK, Singh RK. Therapeutic journey of Andrographis paniculata (Burm.f.) Nees from natural to synthetic and nanoformulations. Mini Rev Med Chem, 2021b; 21(2); 1556-1577. doi:10.2174/13895 57521666210315162354

Mehta S, Sharma AK, Singh RK. Ethnobotany, pharmacological activities and bioavailability studies on "King of Bitters" (Kalmegh): a review (2010-2020). Comb Chem High Throughput Screen, 2021c; doi:10.2 174/1386207324666210310140611.

Mukherjee PK, Rai S, Bhattacharya S, Wahile, A. Marker analysis of polyherbal formulation, Triphala - A well known Indian traditional medicine. Indian J Tradit Knowl, 2008; 7(3):379-83.

Parveen R, Parveen B, Parveen A, Ahmad S. Andrographis paniculata: from traditional to nano drug for cancer therapy. In: Husen
A, Iqbal M (ed.). Nanomaterials and plant potential. Springer, Cham, Switzerland, pp 317-45, 2019.

Patel MB, Kadakia VM, Mishra, SH. Simultaneous estimation of andrographolide and wedelolactone in herbal formulations. Indian J Pharm Sci, 2008; 70(5):689-93.

Poppe L, Petersen M. Variation in the flavonolignan composition of fruits from different Silybum marianum chemotypes and suspension cultures derived there from. Phytochemistry, 2016; 131:68-75.

Serviddio G, Bellanti F, Stanca E, Lunetti P, Blonda M, Tamborra R, Giudetti, AM. Silybin exerts antioxidant effects and inducesmitochondrial biogenesis in liver of rat with secondary biliary cirrhosis. Free Radic Biol Med, 2014; 73:117-26.

Shetty SN, Mengi S, Vaidya, R, Vaidya, ADB. A study of standardized extracts of Picrorhiza kurroa Royle ex Benth in experimental nonalcoholic fatty liver disease. J Ayurveda Integr Med, 2010; 1(3):203-10.

Singh N, Gupta AP, Singh, B, Kaul, VK. Quantification of picroside-I and picroside-II in Picrorhiza kurroa by HPTLC. J Liq Chromatogr Relat Technol, 2005; 28(11):1679-91.

Sinha S, Bhat J, Joshi M, Ghaskadbi S. Hepatoprotective activity of Picrorhiza kurroa Royle Ex. Benth extract against alcohol cytotoxicity in mouse liver slice culture. Int J Green Pharm, 2011; 5(3):244-53.

Srivastava S, Misra A, Kumar, D, Srivastava A, Sood A, Rawat AKS. Reversed-phase high-performance liquid chromatography ultraviolet hotodiode array detector validated simultaneous quantification of six bioactive phenolic acids in Roscoea purpurea tubers and their in vitro cytotoxic potential against various cell lines. Pharmacogn Mag, 2015; 11(44):488-95.

Talmale VR, More PR, Ghumare, BC, Shendre, SB, Nirgulkar, SN. Efficacy of Picroriza kurrooa Benth on experimentally induced hepatotoxicity in cross bred calves. Vet World, 2010; 3(1):29-31.

Wang P, Jiang S, Zhao Y, Sun S, Wen X, Guo X, Jiang Z. A UPLC-MS/MS Method for simultaneous determination of six bioactive compounds in rat plasma, and its application to pharmacokinetic studies of Naoshuantong granule in rats. Curr Pharm Anal, 2019; 15(3):231-42.

Xie Y, Jiang ZH, Zhou H, Cai X, Wong YF, Liu ZQ, Bian ZX, $\mathrm{Xu}, \mathrm{HX}$, Liu L. Combinative method using HPLC quantitative analysis for quality consistency assessment of a herbal preparation. J Pharm Biomed Anal, 2007; 43:204-12.

Xiong K, Shi M, Zhang T, Han H. Protective effect of picroside I against hepatic fibrosis in mice via sphingolipid metabolism, bile acid biosynthesis, and PPAR signaling pathway. Biomed Pharmacother, 2020; 131:110683.

Ye JF, Zhu H, Zhou ZF, Xiong RB, Wang XW, Su LX, Luo, $\mathrm{BD}$. Protective mechanism of andrographolide against carbon tetrachloride induced acute liver injury in mice. Biol Pharm Bull, 2011; 34:1666-70.

Zahiruddin S, Khan W, Nehra R, Alam MJ, Mallick MN, Parveen R, Ahmad S. Pharmacokinetics and comparative metabolic profiling of iridoid enrich fraction of Picrorhiza kurroa - An ayurvedic herb. J Ethnopharmacol, 2016; 197:157-64.

Zhu XX, Ding YH, Wu Y, Qian LY, Zou, H, He Q. Silibinin: a potential old drug for cancer therapy. Expert Rev Clin Pharmacol, 2016; 9(10):1323-30

How to cite this article:

Mehta S, Sharma AK, Singh RK. Method validation for the simultaneous estimation of three-bioactive components in combined extracts of three hepatoprotective plants using RPHPLC method. J Appl Pharm Sci, 2021; 11(07):127-131. 